\title{
Psychiatry in Algeria
}

\author{
Ihsan AL-Issa, Professor of Psychology, The University of Calgary, 2500 University \\ Drive NW, Calgary, Alberta, Canada T2N 1N4
}

In recent years, there has been increasing interest in the development of psychiatry in the Arab countries. Several reports have dealt with psychiatric problems in Iraq, Kuwait and Saudi Arabia (Al-Issa \& Al-Issa, 1970; Kline, 1963; Dubovsky, 1983). Two general reviews have also dealt with major psychiatric research in the Arab Middle East (El-Islam, 1982; Racy, 1970). However, the countries surveyed have been under British and American influence and tend to follow the Anglo-Saxon psychiatric model. Little attention has been given to North African Arab countries which follow the French and franco-phone approach to psychiatry.

The present article deals with aspects of psychiatry in a North African country, Algeria. First, it describes the Algerian sociocultural background and traditional concepts of mental illness and its treatment. This is followed by an overview of the current psychiatric scene with a brief description of psychiatric facilities and current classification and research findings related to the influence of culture on mental illness. The information was collected in Algeria during the academic year of 1986-1987, and is based on interviews with Algerian psychiatrists and a review of psychiatric research. Since the Algerian sociocultural background is similar to that of Morocco and Tunisia, many of the psychiatric findings and information could be generally applied to these countries.

Algeria is the second largest African country after the Sudan. It consists of a narrow fertile littoral which is separated from the Sahara by the high plateau including the Atlas mountains. Like its land, its weather is also varied from the extreme heat of the desert in the south to the winter snow in the high plateau and the mild Mediterranean climate in the north.

In 1962, the year of independence, the population of Algeria was estimated at $10,236,000$, but this number had more than doubled by 1987 , with around one million Algerians residing abroad, mainly in France. The population growth is at the rate of $3.2 \%$ with an average family size of 7.2 in 1982. A married woman will have an average of five children by the age of 25 . Most of the population inhabit the urban coastal areas with $20 \%$ in rural areas and $10 \%$ in the Sahara region. With the exodus of the French after independence in 1962, the cities were flooded with poor, uneducated and superstitious peasants who lacked any experience in modern urban living. Thus, the cities became overcrowded. For example, the 500,000 European inhabitants of Algiers were replaced by three million of predominantly peasants and their children. With the exception of a small number of older former members of the liberation army, the country is run by a first generation of young persons.

Throughout a major part of its history, Algeria was exposed to various invasions such as those from the Phoenicians, Romans, Vandals, Arabs, Spaniards, Turks and French. However, the Arab invasion and French colonialism have left indelible effects on the country and its people. The Arabs in the 7th century brought with them Islam which still remains one of the major forces in the life of Algerians. Also, Arabic which is the language of the Koran, the Muslim holy book, became the national language of the country. French colonialism, which lasted between 1830-1962, had drastic effects on the social and cultural life of the native inhabitants. Unlike other French colonies, Algeria was considered as a part of France and consistent efforts were made to eradicate its old original culture and integrate it with the mother country. Nevertheless, Algerians did not benefit from French social welfare and services in the areas of education and health. For example, Algerians were $85 \%$ of the total population in $1937-1938$ but they contributed only $7.2 \%$ of high school students. There were only 89 Algerian students in the University of Algiers in 1940 and that number increased to 500 (out of 5000 ) in 1954. Double standards were applied in the segregated hospital wards. There was a prevalent belief among Algerian patients that one went to hospital for dying and it was better to die at home among one's own people.

Being dispossessed of cultivated land during the French colonial era, the majority of Algerians became daily workers on the farms of the colonialists. Lack of employment in the countryside forced a large number to migrate to the large urban centres to live in shanty towns in the outskirts of cities. Because of the loss of their own plots of cultivated land to the colonialists and the lack of paid work, the majority of Algerians lived in degrading poverty which is well described by Albert Camus and by the 
Algerian novelist Maouloud Feraoun. The French also encouraged tribalism and regionalism and attempted to widen the gap between the two major ethnic groups in the country, the Arabs and the Berbers. Since the Berbers speak their own language, the schooling of their children was in French which later became the main means of communication between them and the Arabs. Because schooling used to be limited for most Algerians during the colonial period, they may not have had the opportunity to learn French and it is not unusual today to find a situation where an Arab cannot communicate with a Berber, even when the latter speaks French in addition to his own native language.

Despite the cultural and material poverty of Algerians during the colonial period, many cultural and social features of the society resisted change. Algeria remains a Muslim society, with religion as a strong unifying factor among different ethnic groups. Islam provided the poor peasants with a spiritual outlet from a miserable existence and a hope for a better after-life. The Algerian individual has also remained loyal to the extended family where the father or the oldest son holds absolute power for decision-making.

\section{Traditional concepts of mental illness and its treatment}

A major aetiological concept of mental illness in Algeria as well as in other parts of the Arab world is related to possession and control by the Jinn (spirits) Jinnoon, which means madness, is derived from the word Jinn. The cause of mental illness is regarded as exterior to the individual and often considered as a result of persecution and sorcery.

A popular cause of both physical and mental illness is the evil eye which may be motivated by the envy, jealousy or even admiration of an enemy or a friend. In traditional Algerian society, the evil eye is a sanction against anybody who exceeds the limits put by society such as wealth, beauty and happiness. Another aetiological factor is tankir (denial) which explains indifference to one's social environment, particularly to those whom one loves. Tankir could account for social withdrawal (in schizophrenia) and loss of interest in the social environment (in depression). This state is induced by a witch and may be used by a woman to regain the lost love of a man, or by a parent to bring back a son who left the extended family to live separately with his wife, or by a wife to reduce the influence of her husband's family.

Male sexual dysfunction is regarded as a female persecution and the result of witchcraft. A jealous woman may want to destroy a marriage by casting a spell on the husband and thus 'knotting' him. The wife may also be accused of bewitching her husband.
'Knotting' as a form of magical control is known in other Arab countries as well as in Western witchcraft. Traditional Algerian families may intentionally use 'knotting' on their daughters by symbolically locking a padlock to induce vaginismus in order to protect their virginity before marriage. The padlock has to be safely kept to be unlocked later just before marriage; its loss is considered a major cause of vaginismus. 'Knotting' may be brought about or counteracted through the mediation of a 'holy' man who has special powers of conjuring the spirits.

In Arab countries such as Kuwait and Tunisia the practice of traditional therapy is illegal. This is partly the result of pressure from the medical establishment and the desire of governments for Westernisation and their distate of indigenous practices. With urbanisation and the increase of Western education after independence, it was expected that the utilisation of traditional therapy would decrease in Algeria. However, this therapy is not only legal, but is also on the increase. According to Bensmail, Merdji \& Touari (1984), acculturation and social change have made the new generation so insecure that they are reverting to traditional therapists and indigenous remedies.

One traditional North African therapist is the taleb, who carries out religious teaching in addition to his function as a healer. In therapy, he may recite verses from the Koran or give the patient an amulet (herz) to carry around or soak a paper with religious writings in water for the patient to drink (MaMahoo). The other traditional therapist is the marabout, who is a saint, an exorcist and a healer. His functions in North Africa are equivalent to those of a sorcerer in black Africa. During exorcism, the marabout converses with the evil spirit through the patient. He may appeal or threaten the evil spirit by repeating a religious-magical formula, burning incense and offering a sacrifice of a black cock. The marabout may simply beat the patient with a stick as a last resort to get rid of the evil spirit. Patients often visit a shrine of a marabout, to honour him by offerings and food festivities (Zerda or Casaa). A therapeutic session (Hadra) which includes exorcism may be carried out by a descendant of the dead marabout. Even recovery from mental illness after psychiatric treatment may be followed by a ceremony with offerings and sacrifices for a marabout. Finally, a patient may also see a clairvoyant who specialises in dealing with emotional and sexual problems (male sexual dysfunction and sterility). In general, women tend to use traditional therapists more than men.

\section{The present psychiatric scene}

For the majority of Algerians, the use of psychiatric services is still limited to emergencies. One group of 
patients seen by psychiatrists are those who are considered to be a danger to the self or others; they tend to be the suicidal, the acute psychotics (confused, manic, and agitated) and the paranoid cases with delusions of persecution. Another group are the catatonic, stuporose and confused patients. Patients often arrive at the psychiatric clinic accompanied by a retinue of family members after exhausting all other possibilities for traditional therapy.

All four universities at Algiers, Annaba, Constantin and Oran have medical schools with departments of psychiatry. In 1985, there were 250 psychiatrists in the whole country which included only 120 Algerians (the number of Algerian psychiatrists had increased to 150 in 1987). Most foreign psychiatrists are from the Eastern bloc with no knowledge of native languages. They cannot communicate directly with patients and often need a French translator during the psychiatric interview.

At the time of independence, there were only three mental hospitals in the whole country, but by 1987 this number had increased to ten, including two hospitals in Algiers, the capital. There are also out-patient clinics and psychiatric wards in the main general hospitals. Hospital admission tends to reach a peak during the summer months, but is at its lowest during the Muslim fasting month of Ramadan.

There is still no trained clinical psychologist in the whole country. However, graduates with a bachelor degree in psychology are employed in mental hospitals with the limited function of psychological testing. There is a department of social-clinical psychology in the Institute of Psychology and Educational Sciences at the University of Algiers, but its programme is more similar to those of educational psychology in Anglo-Saxon countries. After independence, social workers employed by the ministry of health had three years of training after primary school, but this program now only accepts graduates from high school.

\section{Culture and mental illness in Algeria Classification}

Recently, three North African psychiatrists from Tunisia, Morocco and Algeria edited a Manual of Psychiatry for the North African Practitioner (Douki, Moussaoui \& Kacha, 1987). The manual reflects the influence of French psychiatry, particularly the diagnostic system published by Ey, Bernard \& Brisset (1973). The translated version of DSM-III (DSMIII, 1985) has only a minor influence such as in the definition and classification of phobias and anxiety states. Overall, the manual tends to use a combination of descriptive categories and theoretical notions quite similar to DSM-II (American Psychiatric Association, 1969). Neurosis, for example, is differentiated from psychosis and is regarded as related to intrapsychic conflicts. Similarly, hysterical neurosis is defined as symbolic of underlying intrapsychic conflicts. Another particular feature of the manual is the inclusion of chapters on epilepsy and mental problems associated with infectious disease (the latter is presented separately from psychosomatic disorders). It is interesting that as much space is devoted to epilepsy as to schizophrenia or depression.

Chronic delusional psychoses and bouffées délirantes which are part of French nosology are also considered as major categories of mental illness in the manual. One example of chronic delusional psychoses is the 'psychoses of passion' which include erotomania (the delusion that one is loved by someone else), delusion of jealousy and delusions of revenge (which may be labelled as querulant delusions or litigious paranoid states).

Much more has been written in the African francophone literature and by Anglo-Saxon authors on the syndrome of bouffées délirantes. This syndrome is characterised by a sudden onset with vivid hallucinations, delusions, clouding of consciousness and rapid mood swings. Themes of delusions are related to religion (prophetic inspiration, divine revelation, messianic conviction, end of the world and resurrection), sexuality, jealousy, poisoning, bewitchment, and persecution. Some of the stressful life events related to the syndrome are sudden death, migration, forced marriage, sexual abuse, and incest. A frequent type of bouffées délirantes is nuptial psychosis which happens the day after marriage as a result of the stresses involved in arranged marriage and experienced by the bride. In general, patients with bouffées délirantes tend to be mostly females between the age of 20 and 30.

The Anglo-Saxon classification of mental illness has no category which is equivalent to bouffées délirantes "that one can use for acute psychotic episode ... that does not imply a known aetiology (brief reactive psychosis) or a relationship to another grouping (schizophreniform psychosis) or else is so vague that cases categorised within it may bear no resemblance to each other (e.g. atypical psychosis (Kroll, 1979, p 1137)." Although bouffées délirantes are frequently diagnosed in North Africa, psychiatrists in other Arab countries are not familiar with it, raising the question whether the presence of this label in the French nosology facilitates the identification of cases that conform to it.

\section{Depression}

The picture of depression is dominated by the prevalence of somatic symptoms. Mood disturbance is, however, either minor or not verbalised at all by the patient. Reluctance to express depressive mood may be related to the observation that in North 
Africa children and adults are taught to be ashamed of the expression of their feelings outside an institutionalised framework such as during bereavement, weddings and childbirth.

Self-depreciation and guilt feelings are rarely observed in depressive patients, although these symptoms have been recently increasing in frequency.

Other delusions are frequently observed in North African depressive patients to such an extent that one of the most frequent subtypes of depression seen by psychiatrists is called delusional depression or delusional melancholia with the characteristic themes of persecution, bewitchment, possession and poisoning sometimes accompanied by aggressive behaviour (the other most frequent subtype is masked depression). The diagnosis of delusional depression is often confused with bouffées délirantes or schizophrenia, but the illness tends to respond to antidepressives rather than neuroleptics. The presence of delusions of persecution and aggression in depressive patients is also found in other Arab countries. Ammar (1975) noted that the most frequent mechanisms in health and illness used by North Africans are flight into fantasy and imagination, projection and the experience of morbid jealousy and hostility. These mechanisms are expected to be more conducive to delusions and aggressive behaviour. Delusions of persecution are so frequently found in different types of psychiatric patients (consider for example hystero paranoiaque syndrome reported by Bensmail, Torki \& Touari (1981)), that they may be considered as an exaggeration of the Algerian normal personality.

\section{Suicide}

In traditional rural Algerian communities, there is a low rate of suicide, which is comparable to those in other Muslim societies. In urban areas, however, there has been a substantial increase in the rate of suicide among the young and the unemployed. Females predominate in all age groups, particularly between the ages of 15 and 22 (in the traditional setting the rates are slightly higher among males). A first generation of educated women in this patriarchal peasant society finds it difficult to accept their inferior position. Muslim religion which regards suicide as sinful still has some preventive effect on the rates of suicide in urban communities; they are at their lowest during the Muslim fasting month of Ramadan.

\section{Schizophrenia}

Before independence it was believed that while bouffées délirantes were frequent in traditional society, schizophrenia used to be very rare. However, since the sixties the situation has been changing; the number of schizophrenic subjects in Algeria has increased from $18 \%$ of total in-patients in 1964 to $30 \%$ in 1974 and reached $36 \%$ and $40 \%$ in 1977 and 1985 respectively (Bensmail, 1987). Bensmail attributes this noticeable increase to the availability of psychiatric services and the intolerance of patients in an urban environment.

Using the Present Status Examination on 25 schizophrenic subjects, Kacha \& Kessaci (not dated) found that the patients were either suffering from paranoid schizophrenia (18 cases) or hebephrenia (seven cases). The study confirmed the presence of Schneiderian symptoms such as somatic passivity, thought insertion, thought broadcast, thought withdrawal, delusions of influence and auditory hallucinations. The average age of admission of this group was 22, but there was no relationship between the age of admission and prognosis (patients admitted to hospital were a selected group of the agitated and other emergency cases). Stressful life events found to be associated with schizophrenic breakdown were not different from those found in Western countries (engagement, marriage, death of a parent, physical trauma, surgery, high school examination and recruitment into the army). The youngest child tended to be the most vulnerable to the illness. Another study found that many possessive states tended to develop later into schizophrenia.

Arranged marriage with a relative is part of traditional Algerian society and the study of parental consanguinity in schizophrenia is expected to contribute to the understanding of the inheritance of the illness. In the general population, parental consanguinity is $34 \%$ in rural and $29 \%$ in urban areas. Bensmail \& Moron (1979) found that parental consanguinity among schizophrenic subjects was $50 \%$ with the most severe cases (33\% of patients) combining parental consanguinity and a family history of mental illness.

\section{Drug abuse and alcoholism}

The use of cannabis (kif, hashish) is tolerated in traditional North African society. The drug user is typically a normal married adult whose cultural values and moral principles are not different from the rest of society. But the traditional picture has recently changed into a more compulsive intake of drugs despite repressive legislation against their use. Cannabis remains the principal drug, but its derivatives are now stronger and it is taken together with prescribed drugs.

Although alcohol is used despite its prohibition in Islam, it has never become popular among the North African masses. Drinking in Algeria is almost a masculine behaviour that takes place outside the home (bringing alcohol into the home is taboo in traditional Muslim society). There is also an almost complete abstention from alcohol during the Muslim fasting month of Ramadan. Social and religious 
factors which limit the occasions for drinking may explain the ability of alcoholics and heavy drinkers to abstain from drinking for a long period without major problems. With urbanisation and breakdown of the traditional Muslim family, drinking is becoming a cause of social and family problems such as accidents and divorce. Cases of alcoholism and psychosis associated with addiction increased from $1 \%$ to $6 \%$ of total admissions to a mental hospital in the city of Constantin between 1964 and 1975. In a later study of 706 patients admitted to a mental hospital in Algiers, $7 \%$ (51 cases) were males suffering from alcoholism and other addictions. Chronic alcoholism was however, quite rare. Sixty-eight per cent of the cases (34 out of 51) suffered from psychiatric disturbances such as anxiety, depression and serious personality problems. Kacha \& Akrour (1986) compared this high level of psychiatric disturbance with only $3 \%$ found among alcoholics in Spain.

\section{Further cultural observations}

With the exception of hysteria, other types of neuroses such as phobia and obsessive-compulsive disorder are rare in traditional Algerian society and other North African countries, although psychiatrists observe that their rates are on the increase in some urban centres.

In Muslim countries, including North Africa, obsessive-compulsive disorder or Waswas is associated with the Muslim ritual of ablution and prayer. "The sufferer of Waswas finds it hard to terminate the ablutions because he is afraid that he is not yet clean enough to carry out his prayer in the lawful manner. Similarly, he will repeat the introductory invocations and the raising of the arms more times than is called for, because he feels that his thinking is not yet fully focused on God. Finally, at the end of the prayer he may be beset by doubts about whether he might perhaps have forgotten some words, so he will start all over again from the beginning"' (Pfeifer, 1982 , p. 212). Waswas is not conceived as an illness that could be treated, but it is considered instead as a temptation by the devil that is aimed at distracting the person from carrying out his religious duties and therefore should not be given undue attention.

With the exception of impotence and vaginismus, cases with other sexual problems are rarely seen by psychiatrists. Impotence and vaginismus are often caused by anxiety on the wedding night when the whole extended family awaits the consummation of the marriage and the verification of the virginity of the bride. In Algeria, premature ejaculation is positively viewed rather than being considered as an abnormality. Homosexuality hardly comes to the attention of psychiatrists as the primary reason for consultation. A study of a group of patients with sexual problems reported two cases of homosexuals: a paranoid personality and a transvestite prostitute who had no desire for change but came for consultation in order to be able to get married and to have children to fulfill a promise he had made to his mother.

One serious problem in Algerian cities is that of abandoned infants and infanticide which is a direct result of negative attitudes towards premarital sexuality and pregnancy outside marriage. The majority of these women who commit infanticide or abandon their children are single, divorced or widowed whose behaviour is not motivated by mental illness (depression, schizophrenia) but by their fear of loss of social status. A single mother cannot pursue the father in the courts or give the child for adoption (fostering a child is possible, but adoption is illegal). Giving the child the mother's family name implies promiscuous sexual behaviour which brings disgrace, shame and social rejection. Therefore, infanticide or simply abandoning the child may be the only alternative resort for the mother (Boucebci, 1977).

Heart disease constitutes a major cause of death after the age of 50. A study of blood pressure by Geidel (1979) shows that it increases with age, and this increase is higher among women. He also found that in all age groups women have higher blood pressure than men. In contrast, cross-cultural research reveals that while men tend to have higher blood pressure at a younger age, women only start surpassing men during middle age. However, consistent with Western data, Geidel found that neither the number of children nor the age of menopause were related to the development of hypertension in Algerian women. Blood pressure was associated with social class. The highest blood pressure was found among workers, followed by shopkeepers with the lowest level among those from an agricultural environment.

Finally, many culture-specific family stresses such as the absence of migrant fathers, bigamy, successive marriages and large number of children are associated with mental illness. The families of migrant fathers are found to have a high risk of mental illness. This is particularly true for the oldest son who replaces the father and takes responsibility for his younger brothers and an illiterate mother; he represents the highest risk for psychosis and other psychiatric disorders. Boucebci (1985) observed that childhood psychosis tends to be rare in the traditional extended family with a large number of children. However, with the gradual disappearance of the traditional setting of social support and multiple mothering, the quality of care tends to deteriorate in large families. Since the later born children receive less care, they tend to have higher risk of mental illness. Young mothers in large families are also affected with high rates of confusional psychotic states and post-partum depression. 


\section{References}

AL-Issa, I. \& AL-IssA, B. (1970) Psychiatric problems in a developing country: Iraq. International Journal of Social Psychiatry, 16, 15-22.

American Psychiatric Association (1969) Diagnostic and Statistical Manual of Mental Disorders (2nd ed.). Washington, DC: APA.

AmMAR, S. (1975) Ethnopsychiatrie et psychiatrie transculturelle: Introduction aux problèmes posés par l'impacte de l'acculturation sur la santé mentale au Maghréb. $\mathbf{L a}$ Tunisie Medicale, 6, 315-330.

Bensmall, B. (1987) Schizophrenies. In Manuel de Psychiatrie du Praticien Maghrébin (eds. S. Douki, D. Moussaoui \& F. Kacha).

- \& Moron, P. (1979) Culture traditionelle, consanguité et facteurs génétiques psychiatriques. Comptes Rendus du Congres de Psychiatrie et de Neurologie de Langue Franfaise (Charleroi, Belgium, 26 June-1 July 1978). Paris: Masson.

-, Bentorki, H. \& TouARI, M. (1981) La dépression en Algerie: Aspects culturels et evolution epidemiologique. Psychiatrie Francophone. No. 0-4e Trimestre, 10-19.

-, Merdjl, Y. \& Touari, M. (1984) Pensée magique et therapies traditionelles. Psychiatrie Francophone. No. 3-4, 28-33.

BOUCEBCI, M. (1977) La psychiatrie infanto-juvénile en Algérie. Acta Psychiatrica Belgica, 77, 587-622.

- (1985) Le handicap mental: Aspects épidémiologiques de prise en charge et preventifs en Algéri. Comple Rendu de Congress Medical Meghrébin, Monastir. Tunisie.
Douki, S., Moussaoui, D. \& KaCha, F. (1987) Manuel de Psychiatrie du Praticien Maghrébin. Paris: Masson.

Dubovsky, S. L. (1983) Psychiatry in Saudi Arabia. American Journal of Psychiatry, 140, 1455-1459.

El-IsLAM, M. F. (1982) Arabic cultural psychiatry. Transcultural Psychiatric Research Review, 19, 5-24.

Ey, H., Bernard, P. \& Brisset, C. L. (1973) Manuel de psychiatrie (5th ed.). Paris: Masson.

GEIDEL, J. M. (1979) Etude épidémiologique de l'hypertension artérielle à Constantine. These de Medicine, University of Paris.

KACHA, F. \& KESSACI, M. (n.d.) 25 schizophrènes deux ans après: Resultants preliminaires. XIe Journées medicochiruguicales de l'Armee Nationale Populaire, Algiers, Algerie.

-\& AKROUR, A. (1986) Approche du toxicomane hospitalise en milieu psychiatrique. Zième Journée de Psychiatrie Algerién, Algiers, Algeria.

KLINE, N. S. (1963) Psychiatry in Kuwait. British Journal of Psychiatry, 109, 766-774.

Kroll, J. (1979) Philosophical foundations of French and US nosology. American Journal of Psychiatry, 136, 1135-1138.

PFeifer, W. M. (1982) Culture-bound syndromes. In Culture and Psychopathology. (ed. I. Al-Issa). Baltimore, Maryland: University Park Press.

RACY, J. (1970) Psychiatry in the Arab East. Acta Psychiatrica Scandinavica. Supplement No. 211.

A full list of references is available on request from the author. 